\title{
Vasopressin Stimulation of Adrenocorticotropin Hormone (ACTH) in Humans In Vivo Bioassay of Corticotropin-releasing Factor (CRF) which Provides Evidence for CRF Mediation of the Diurnal Rhythm of ACTH
}

\author{
R. A. Salata, D. B. Jarrett, J. G. Verbalis, and A. G. Robinson \\ Departments of Medicine and Psychiatry, University of Pittsburgh, Pittsburgh, Pennsylvania 15261
}

\begin{abstract}
The diurnal response of ACTH release to intravenously administered arginine vasopressin was tested in normal volunteers given consecutively moderate doses of vasopressin every $15 \mathrm{~min}(0.1,0.3,1.0$, and $3.0 \mathrm{IU})$ at $2200 \mathrm{~h}$ and again at $0700 \mathrm{~h}$ (PM/AM). This protocol was repeated 4 wk later with the times reversed (AM/PM). A dose-related increase in ACTH secretion was observed in all subjects. When the $A M$ response of the AM/PM protocol was compared with the PM response of the PM/AM protocol, the release of ACTH was greater in the morning $(P<0.05)$ as evaluated by the following criteria: peak value of ACTH $(129.9 \pm 30.4 \mathrm{pg} / \mathrm{ml}$ in the $A M$ vs. $57.1 \pm 20.2$ in the PM); area under the curve (689 in the AM vs. 259 in the PM); and, sensitivity of the ACTH dose-response curve (first significant increase in ACTH with 1 IU of vasopressin in the AM but not significant even after $3 \mathrm{IU}$ in the PM). In addition, when the AM vasopressin testing followed a previous evening stimulation (PM/AM protocol), there was a blunted ACTH response compared with the AM/PM protocol. Corticotropin-releasing factor (CRF) is probably the major ACTH secretagogue, but since vasopressin acts synergistically with CRF to produce an augmented release of ACTH, we suggest that the ACTH response to administered vasopressin depends upon the ambient endogenous level of CRF. We interpret our data and published data that CRF produces a lesser release of ACTH in the AM as follows: in the morning endogenous CRF is high and administered CRF produces little further release of $\mathrm{ACTH}$, but administered vasopressin acting synergistically with high endogenous CRF causes a greater release of ACTH; conversely, in the evening endogenous CRF is low and administered CRF causes a greater release of ACTH, but vasopressin (a weak secretagogue by itself) gives a low ACTH response. We conclude that vasopressin stimulation of ACTH secretion can be used as an in vivo bioassay of endogenous CRF, and that there is a diurnal rhythm of CRF in hypophyseal portal blood.
\end{abstract}

\section{Introduction}

ACTH secretion by the corticotrophs in the anterior pituitary is regulated by corticotropin-releasing factor(s) (CRF) ${ }^{1}$ from the hypothalamus $(1,2)$. CRF is probably the major ACTH

Address correspondence to Dr. Robinson, 930 Scaife Hall, Div. of Endocrinology and Metabolism, University of Pittsburgh, School of Medicine, Pittsburgh, PA 15261.

Received for publication 13 May 1987 and in revised form 9 October 1987.

1. Abbreviation used in this paper: CRF, corticotropin-releasing factor.

J. Clin. Invest.

(c) The American Society for Clinical Investigation, Inc.

0021-9738/88/03/0766/09 \$2.00

Volume 81, March 1988, 766-774 secretagogue, but administration of arginine vasopressin (AVP) also stimulates the release of ACTH $(3,4)$. Vasopressin-stimulated release of ACTH or cortisol has been described in man (5), in rats with hypothalamic lesions (6), in rats in which the pituitary has been transplanted to the kidney capsule (7), in isolated pituitaries in organ culture (8), and in dispersed anterior pituitary cells (9). It is unclear whether vasopressin has a physiological role in the regulation of ACTH secretion $(10,11)$. CRF has been shown to be a more potent secretagogue of ACTH than vasopressin $(9,12,13)$, and the greatest response of vasopressin to release ACTH occurred when vasopressin was co-administered with CRF (13-16). In this situation there appeared to be a synergism between both releasing factors to cause an augmented release of ACTH. It was recently shown in humans that concurrent administration of vasopressin and CRF produced a 30-fold increase in the release of ACTH as compared with administration of CRF alone (14).

The well-known diurnal rhythm of plasma cortisol reflects a similar diurnal rhythm of ACTH. ACTH is secreted in a pulsatile fashion with more frequent bursts occurring in the early morning which produce the early morning surge of cortisol (17). Although CRF has not been measured in portal vessels of man, it is hypothesized that the secretory bursts of ACTH result from pulses of CRF secreted into hypophyseal portal blood, with more frequent bursts of CRF occurring in the early morning (17). When CRF was administered to humans, the ACTH and cortisol response was reported to be lower in the morning than in the evening (18-20), but the mechanism of either the augmented sensitivity of the pituitary adrenal axis in the evening, or of the blunted sensitivity in the morning, is not known. Glucocorticoids have been shown to blunt or abolish CRF-induced ACTH release $(21,22)$, and the lower morning response may simply be due to negative feedback. Alternatively, if endogenous CRF is at or near its maximum level in the morning, exogenously administered CRF may cause relatively little augmentation of release of ACTH.

Because vasopressin acts synergistically with CRF to produce an augmented release of ACTH (13-16), we hypothesized that the ACTH response to administered vasopressin might depend on the ambient endogenous level of CRF. Thus, if there is a diurnal rhythm of CRF secretion, administered vasopressin should cause a greater release of $\mathrm{ACTH}$ in the morning, when endogenous CRF levels would be high, than in the evening, when CRF levels would be low. To evaluate this we measured the changes in plasma cortisol and ACTH in the morning and in the evening after infusion of graded boluses of vasopressin in normal human volunteers. We used small graded boluses of vasopressin to obtain a dose-related release of ACTH, as has been described with CRF (23). By obtaining a less than maximal ACTH response, synergism between endogenous CRF and exogenous vasopressin might be demonstrated not only by a difference in the maximum level of ACTH, but also by the threshold at which ACTH was released. 


\section{Methods}

Five healthy volunteers (three females and two males) age 23 to 30 were studied twice at 4-wk intervals at the Clinical Research Center of the University of Pittsburgh. All subjects were nonsmokers, were on no medications, and abstained from alcohol for at least $24 \mathrm{~h}$ before each study. None of the subjects were depressed as judged by the Beck Depression Index, nor had any previous history of psychopathology. The women were studied between days 3 and 12 of their menstrual cycle. The study was approved by the Institutional Review Board for Biomedical Research of the University of Pittsburgh, and informed consent was obtained before each study.

In the first experimental design (PM/AM protocol), the patients had a light dinner and then had nothing further by mouth until the next morning. At $2000 \mathrm{~h}$ an intravenous line was inserted into an antecubital vein for infusion of vasopressin and withdrawing of blood. Normal saline, $0.9 \% \mathrm{NaCl}$ solution, was infused at a rate sufficient to keep the intravenous line patent. Aqueous pitressin (Parke, Davis \& Co., Detroit, MI, synthetic vasopressin, $20 \mathrm{U} / \mathrm{ml}$ ) was diluted in sterile $5 \%$ dextrose and water to a final concentration of $1 \mathrm{U}$ vasopressin per 5 $\mathrm{cm}^{3}$ before infusion. The patients remained supine until testing was completed. At $2200 \mathrm{~h}$, which was designated 0 time, the vasopressin stimulation was initiated with $0.1 \mathrm{U}$ vasopressin infused intravenously over $1 \mathrm{~min}$. At 15-min intervals thereafter, graded boluses of vasopressin were infused intravenously over $1 \mathrm{~min}$ as follows: $0.3 \mathrm{U}$ at +15 min, $1.0 \mathrm{U}$ at $+30 \mathrm{~min}$, and $3.0 \mathrm{U}$ at $+45 \mathrm{~min}$. Blood samples for $\mathrm{ACTH}$, cortisol, and vasopressin levels were obtained at $-15 \mathrm{~min}, 0$ time, every $5 \mathrm{~min}$ from 2200 through $2300 \mathrm{~h}$, and then every $15 \mathrm{~min}$ for the next $45 \mathrm{~min}$. During the graded vasopressin infusion, blood pressure and pulse were monitored before and after each dose increase. At $0700 \mathrm{~h}$ the next day, the graded vasopressin infusion was repeated after the same protocol as the previous evening infusion.

The second study (designated AM/PM) was performed 4-8 wk after the first study. The experimental design was exactly as outlined in the first study, except that the time of day of the vasopressin infusion was reversed, with the subjects being tested first in the morning after an overnight fast and then again in the evening of the same day.

Blood samples for assay of ACTH were collected into chilled plastic tubes containing EDTA and aproptinin and were immediately placed on ice. Within $5 \mathrm{~min}$ of collection the blood was centrifuged at 10,000 $g$ for $5 \mathrm{~min}$ at $4^{\circ} \mathrm{C}$ and the plasma supernatant transferred to plastic tubes containing $N$-ethylmaleimide at a concentration of $0.01 \mathrm{M}$. The plasma was rapidly frozen and stored at $-70^{\circ} \mathrm{C}$ until assay, which was always within $3 \mathrm{~d}$. Before assay, the plasma samples were thawed at $4^{\circ} \mathrm{C}$ and extracted using $125 \mathrm{mg} / \mathrm{ml}$ silicic acid. The ACTH was eluted from the silicic pellet with acid methanol. This eluate was air dried and then reconstituted in assay buffer. Recovery was monitored using a standard plasma to which a known amount of $\left[{ }^{35} \mathrm{~S}\right] \mathrm{ACTH}$ had been added and was $70-80 \%$.

Blood for cortisol was collected in Vacutainer (Becton-Dickinson \& Co., Orangeburg, NY) tubes containing 143 U heparin, centrifuged, and frozen as above until assayed. Plasma cortisol was measured by a radioimmunoassay using an antibody specific for cortisol (Endocrine Sciences, Tarzana, CA). Plasma was stored at $-70^{\circ} \mathrm{C}$ until the cortisol radioimmunoassay was performed. For assay, the samples were thawed and an aliquot diluted $1: 51$ in $1 \mathrm{ml}$ of a PBS, $0.1 \%$ gelatin solution, $\mathrm{pH}$ 7. The diluted samples were capped and incubated in a water bath at $85^{\circ} \mathrm{C}$ to destroy the endogenous cortisol binding globulin and release the cortisol. The samples were then cooled and 50- $\mu \mathrm{l}$ aliquots pipetted into $12 \times 75$-mm culture tubes. A standard response curve was prepared with cortisol over the range 0 to $300 \mathrm{pg}$. These tubes were air dried at $45^{\circ} \mathrm{C}$ and then $5 \mu \mathrm{l}$ of PBS-gelatin added. An appropriate tracer solution $\left(11 \mu \mathrm{Ci},\left[1-2-6-7{ }^{3} \mathrm{H}\right]\right.$ cortisol $[100 \mu \mathrm{Ci} /$ $\mathrm{mM}$ ) was air dried and diluted in PBS-gelatin; after mixing, an appropriate volume of cortisol antiserum was added. The tubes were mixed and incubated at room temperature for $2 \mathrm{~h}$ and then overnight at $4^{\circ} \mathrm{C}$. The bound cortisol was separated using $1 \mathrm{ml}$ of a charcoal dextran solution at $4^{\circ} \mathrm{C}$. After addition of the charcoal, the tubes were left for $15 \mathrm{~min}$ at $4^{\circ} \mathrm{C}$ and then centrifuged at $2,200 \mathrm{~g}$ for $15 \mathrm{~min}$ at $4^{\circ} \mathrm{C}$. The assay tubes were decanted into scintillation vials into which $10 \mathrm{ml}$ of a Triton X-100-based scintillation cocktail was added. The vials were shaken for $1 \mathrm{~h}$ and then counted in an LS 8100 scintillation counter (Beckman Instruments, Inc., Irvine, CA). Plasma cortisol values were generated by computer from the standard response curve using a log-dose-logit transformation which linearizes the standard curve.

For ACTH assay we used an antibody provided by Drs. D. Gann and $\mathrm{D}$. Carlson that is a rabbit antibody directed against porcine $\mathrm{ACTH}_{1-39}$. Synthetic human ACTH $\mathrm{H}_{1-39}$ supplied by the National Institutes of Health (NIH), Bethesda, MD, was handled in the manner suggested in their protocol. The original ACTH was stored at a concentration $>200 \mu \mathrm{g} / \mathrm{ml}$ in $0.01 \mathrm{~N} \mathrm{HCl}$ and aliquots diluted in acidified albumin saline solution $(42.6 \mathrm{ml} 12 \mathrm{~N} \mathrm{HCl}, 1 \mathrm{~g}$ Cohn fraction $\mathrm{V}$, and $8.5 \mathrm{~g} \mathrm{NaCl}$ per liter of distilled water), and stored at $-70^{\circ} \mathrm{C}$. ACTH was iodinated with ${ }^{125}$ I to a specific activity of $\sim 200 \mu \mathrm{Ci} / \mu \mathrm{g}$ using IodoGen (Pierce Chemicals, Rockford, IL) (24). The contents of the reaction vessel were transferred to a $0.9 \times 25-\mathrm{cm} \mathrm{G-25} \mathrm{Sephadex} \mathrm{column}$ equilibrated in $0.05 \mathrm{M} \mathrm{Na}$ acetate buffer, $\mathrm{pH} 5.0$, with $1 \%$ BSA. Fractions of $0.5 \mathrm{ml}$ were collected from the column and the protein peak pooled. Aliquots of $100 \mu \mathrm{l}$ were placed in $1.5 \mathrm{ml}$ polypropylene microfuge tubes which were stored at $-20^{\circ} \mathrm{C}$. Before each assay an aliquot of ${ }^{125} \mathrm{I}$-ACTH was purified using HPLC. The ${ }^{125} \mathrm{I}-\mathrm{ACTH}$ peak was then diluted in assay buffer ( $0.3 \mathrm{M}$ Na phosphate buffer, $\mathrm{pH} 7.4$, containing $0.1 \%$ lysozyme and 15,000 kallikrein inhibitor units of aprotinin), to give $\sim 2,500 \mathrm{cpm} / 100 \mu \mathrm{l}$, which resulted in a tracer mass of $5 \mathrm{pg} / \mathrm{in}$ cubation. The assay was set up in $12 \times 75$ polypropylene tubes using a final antibody dilution of $1: 18,000$ with standards over the range of 0 to $5,000 \mathrm{pg} / \mathrm{ml}$ in a final volume of $250 \mu \mathrm{l}$. The antibody and standards/unknowns were preincubated for $4 \mathrm{~h}$ at $4^{\circ} \mathrm{C}$ before the freshly chromatographed ${ }^{125} \mathrm{I}$-ACTH was added. After overnight incubation at $4^{\circ} \mathrm{C}$, a sheep anti-rabbit gamma globulin second antibody, diluted 1:20 in 4\% polyethylene glycol, was added and incubated for $4 \mathrm{~h}$ at $4^{\circ} \mathrm{C}$. The bound hormone was separated by centrifugation at $10,000 \mathrm{~g}$ for $3 \mathrm{~min}$ at $4^{\circ} \mathrm{C}$. The supernatants were aspirated and the tubes counted in a Gamma 8000 counter (Beckman Instruments, Inc.). The assay has a sensitivity of $5 \mathrm{pg} / \mathrm{ml}$. As with the cortisol assay, the values are generated by computer, using the log dose-logit plot (25).

Plasma AVP was assayed as described previously (26). For statistical analysis, pretest values for ACTH and cortisol were defined as the mean of the $-15 \mathrm{~min}$ and 0 time values. However, when subtracting baseline values of ACTH and cortisol the lowest point of the initial sampling was used, because ACTH and cortisol values fell initially after the pretest values in some subjects, reflecting the normal diurnal fluctuations in these hormones. The area under the curve for ACTH and cortisol responses were determined from each subject's individual values after the baseline was subtracted. Student's paired $t$ tests were utilized to determine at which dose of vasopressin there was a response significantly above baseline, and to analyze peak ACTH and cortisol response and area under the curve. Overall differences between trials in ACTH, cortisol, and vasopressin were analyzed using repeated measures analysis of variance. Correlations were determined with regression analysis by the method of least squares.

\section{Results}

Dose-response relationships of administered $A V P$ and plasma $A C T H$ and cortisol. All subjects were monitored closely during the graded vasopressin infusion. A slight but transient increase in blood pressure and pulse was noted only after the 3-U infusion of vasopressin. Additionally, several subjects noted sensations of acral flushing, increased gastrointestinal motility, or nausea after the 3-U bolus, but these sensations all resolved within $30 \mathrm{~s}$.

Every subject had an increase of plasma ACTH and of plasma cortisol during every test, and overall there was a sig- 
nificant relationship between the hormone level and the dose of vasopressin administered both for ACTH, $P<0.01$, and for cortisol, $P<0.01$. In all subjects there was no significant increase in ACTH and cortisol with the lowest dose of vasopressin administered (0.1 U).

The mean plasma ACTH in the morning of the AM/PM protocol (Fig. 1) illustrates the observed stepwise increase in ACTH which allowed definition of threshold response as well as any shift of the dose-response curve to the left or the right. A cumulative effect of administered vasopressin was observed, with each subsequent and larger dose adding to the residual ACTH response produced by the previous dose. The peak ACTH concentration occurred 5-10 min after each dose of vasopressin, but was still elevated by $15 \mathrm{~min}$ when the next dose of vasopressin was given. After the last dose of vasopressin the subsequent decrease in the levels of vasopressin demonstrate a physiologic half-life of $\sim 20 \mathrm{~min}$, which is consistent with the observation that the 15 -min bolus regimen produced a cumulative effect on release of ACTH.

Effect of vasopressin infusion in the morning in comparison with the evening. The vasopressin infusion in the morning of the AM/PM protocol was compared with the same infusion in the evening of the PM/AM protocol, i.e., first exposure to vasopressin in each case. Plasma ACTH levels for each individual subject are illustrated in Fig. 2. The mean pretest ACTH level in the morning was $37.4 \pm 10.1 \mathrm{pg} / \mathrm{ml}$ and in the evening $24.4 \pm 8.7 \mathrm{pg} / \mathrm{ml}$. The morning level was greater than the evening level in all subjects, although the mean levels were not significantly different $(P=0.36)$. The mean pretest cortisol levels were higher in the morning in every subject: morning cortisol, $16.4 \pm 3.0 \mathrm{mg} / \mathrm{dl}$, and evening cortisol, $2.7 \pm 0.6 \mathrm{mg} / \mathrm{dl}$, $P<0.01$. Plasma levels of ACTH in response to the graded vasopressin infusion are shown for each subject in Fig. 2, and were greater in the morning (Fig. $2 A$ ) than in the evening (Fig. $2 B$ ). This difference was statistically significant by the following criteria: the maximum increase of ACTH over baseline was $99.6 \pm 25.8 \mathrm{pg} / \mathrm{ml}$ in the morning and $40.1 \pm 16.6 \mathrm{pg} / \mathrm{ml}$ in the evening, $P<0.05$; the area under the curve determined by cumulative ACTH increase in the morning was $654.4 \pm 168.3$ and $229.7 \pm 82.3 \mathrm{pg} / \mathrm{ml}$ in the evening, $P<0.05$; and there was a shift in the dose-response increase in ACTH (Fig. 3), with the first significant increase in ACTH noted after $1 \mathrm{U}$ of vasopres-

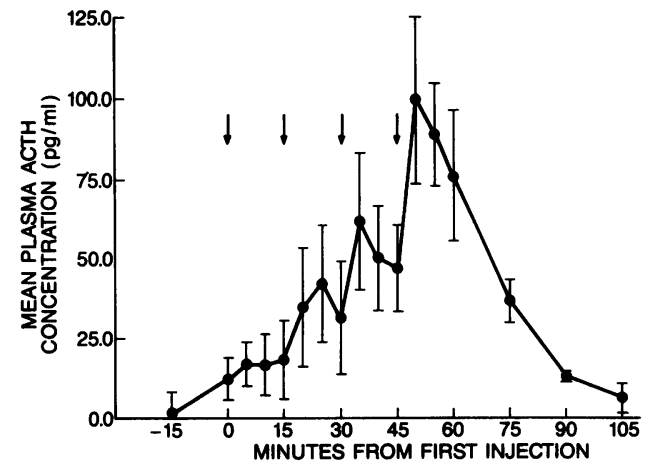

Figure 1. Mean plasma ACTH response ( \pm SEM) of five healthy subjects after graded vasopressin infusion in the morning of $A M / P M$ protocol. The doses of administered vasopressin were submaximal and the stepwise increase in ACTH allowed definition of a threshold response. Dose of vasopressin: $\downarrow, 0.1 \mathrm{IU}$ at 0 time; $0.3 \mathrm{IU}$ at +15 $\mathrm{min} ; 1.0 \mathrm{IU}$ at $+30 \mathrm{~min}$; and $3.0 \mathrm{IU}$ at $+45 \mathrm{~min}$.
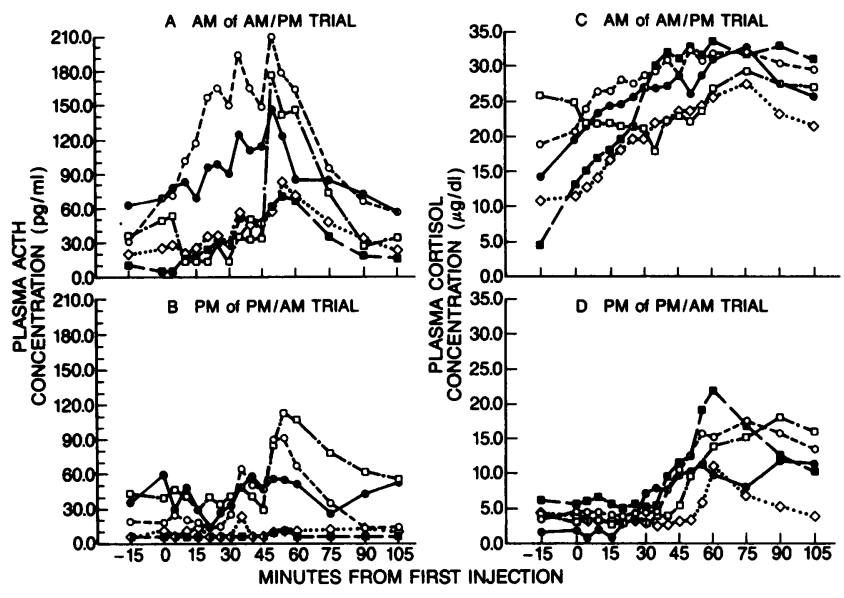

Figure 2. Plasma ACTH for individual subjects in response to administered vasopressin for the morning of the AM/PM protocol $(A)$ and for the evening of the PM/AM protocol (B). Plasma cortisol levels for the same subjects for the morning of the AM/PM protocol $(C)$, and for the evening of the PM/AM protocol $(D)$. Vasopressin doses as in Fig. 1.

sin in the morning $(P<0.05)$. In the evening, even the increase in ACTH after a $3-\mathrm{U}$ dose just missed significance $(P=0.06)$ (Table I).

The individual levels of cortisol are shown in Fig. 2, $C$ and $D$. The maximum increase above baseline of cortisol in the morning, $16.6 \pm 3.2 \mathrm{mg} / \mathrm{dl}$, was greater than the maximum level in the evening, which $11.2 \pm 1.5 \mathrm{mg} / \mathrm{dl}$, but this was not statistically significant. Similarly, the cumulative increment in cortisol in the morning, $175.2 \pm 50.3 \mathrm{mg} / \mathrm{dl}$, was greater than, but not statistically different from the evening cumulative increment in cortisol, which was $70.0 \pm 13.8 \mathrm{mg} / \mathrm{dl}$. There also was not a significant difference in the overall cortisol response patterns between the two trials. There was, however, a shift in

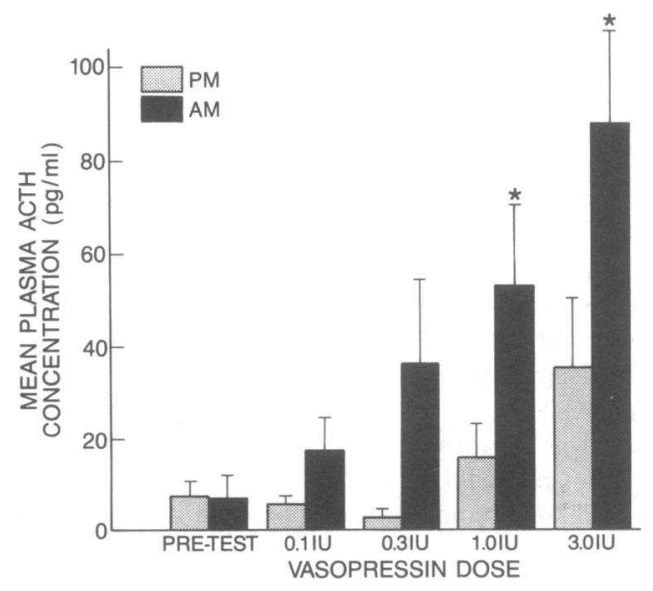

Figure 3. Dose-response increase of ACTH in the morning of the AM/PM protocol versus the evening of the PM/AM protocol. Each bar is the mean of the three ACTH samples for each subject after each dose of AVP. Baseline ACTH levels subtracted for each subject (see text). The ACTH response in the morning is shifted to the left relative to the evening, with the first significant increase in ACTH occurring with $1 \mathrm{U}$ of AVP in the morning. The ACTH response in the evening after $3 \mathrm{U}$ of AVP was $P=0.06$. ( $*$ Significant increase in ACTH compared with baseline value, $P<0.05$ ). 
Table I. Levels of ACTH in Plasma during Each of Four Tests Described in Text

\begin{tabular}{lccccc}
\hline & \multicolumn{2}{c}{ AM/PM Protocol } & & \multicolumn{2}{c}{ PM/AM Protocol } \\
\cline { 5 - 6 } & AM response & PM response & & AM response & PM response \\
\hline & & & $p g / m l$ & & \\
Pretest ACTH & $37.4 \pm 10.13$ & $23.36 \pm 8.0$ & & $34.2 \pm 11.65$ & $24.45 \pm 8.66$ \\
Basal ACTH & $30.30 \pm 25.02$ & $16.92 \pm 18.06$ & & $27.78 \pm 21.18$ & $16.94 \pm 12.36$ \\
Maximum measurement in ACTH & $88.8 \pm 35.37$ & $34.0 \pm 31.24$ & & $33.58 \pm 15.36$ & $40.12 \pm 37.38$ \\
Cumulative ACTH & $654.38 \pm 376.93$ & $189.16 \pm 126.65$ & & $223.14 \pm 108.15$ & $229.68 \pm 185.40$ \\
Dose at which significant ACTH & & & & & \\
$\quad$ increase occurred & $1 \mathrm{IU}$ & None & & $0.3 \mathrm{IU}$ & \\
\hline
\end{tabular}

the dose-response curve for cortisol similar to that found for ACTH. A significant increase of cortisol above baseline was noted after the 0.3-U dose of vasopressin in the morning ( $P$ $<0.05$ ), while in the evening a significant increase was not observed until after a dose of $3 \mathrm{U}$ of vasopressin $(P<0.01$, Fig. 4, Table II).

Effect of prior administration of vasopressin on subsequent response to vasopressin stimulation. The pretest ACTH levels in the morning without prior exposure to vasopressin, $37.4 \pm 10.1 \mathrm{pg} / \mathrm{ml}$, were not significantly different than when vasopressin had been administered the previous evening $(34.2 \pm 11.6 \mathrm{pg} / \mathrm{ml}$, Fig. $5, A$ vs. $C$ ). However, the ACTH response to administered vasopressin was significantly blunted in the morning (Fig. $5 C$ ), when vasopressin had been administered the prior evening, as compared with the response without prior exposure to vasopressin (Fig. $5 \mathrm{~A}$ ). The differences were significant by the same three criteria used to compare the morning with the evening responses: $(i)$ the maximum increase of ACTH above baseline was $99.6 \pm 25.8$ in the morning without prior exposure to vasopressin and $33.6 \pm 6.9 \mathrm{pg} / \mathrm{ml}$ when vasopressin had been administered the prior evening ( $P$ $<0.05$ ); (ii) the area under the curve determined by the cumulative mean incremental ACTH in the morning without prior exposure to vasopressin was $654.4 \pm 168.3 \mathrm{pg} / \mathrm{ml}$, whereas after exposure to vasopressin the previous evening the value was $223.1 \pm 45.0 \mathrm{pg} / \mathrm{ml}(P<0.05)$; and, (iii) the dose-response curve for the morning without prior exposure to vasopressin was shifted to the left relative to the response curve after exposure to vasopressin, with the first significant increase in ACTH after $1 \mathrm{U}$ of vasopressin in the former and after $3 \mathrm{U}$ of vasopressin in the latter.
The ACTH response to administered vasopressin in the evening when there was no prior exposure to vasopressin (PM of the PM/AM protocol, Fig. $5 \mathrm{~B}$ ) was not significantly different when compared with the ACTH response when vasopressin was administered in the morning of the same day (PM of the AM/PM protocol, Fig. $5 \mathrm{D}$ ).

The baseline cortisol levels in the morning were similar in both protocols: $16.4 \pm 3 \mathrm{mg} / \mathrm{dl}$ in the AM/PM protocol, and $12.1 \pm 0.9 \mathrm{mg} / \mathrm{dl}$ in the PM/AM protocol when vasopressin had been administered the previous evening. Likewise, the baseline cortisol levels in the evening were not different: $2.7 \pm 0.6 \mathrm{mg} / \mathrm{dl}$ in the PM/AM protocol and $3.2 \pm 0.8 \mathrm{mg} / \mathrm{dl}$ in the AM/PM protocol when vasopressin had been administered the same morning. However, similar to ACTH, the increment in serum cortisol in the morning was significantly blunted by exposure to vasopressin the previous evening in the PM/AM protocol, as compared with the morning response of $A M / P M$ protocol when no vasopressin was administered previously (Fig. 6). It can also be seen that prior administration of vasopressin in the evening shifted the dose-response curve the next morning to the right, when the morning response of the PM/AM protocol is compared with the morning response of the AM/PM protocol. Again similar to the ACTH response, there was no significant difference in the cortisol levels in the afternoon whether there had or had not been prior exposure to vasopressin within the same $24 \mathrm{~h}$ (PM of AM/PM protocol vs. PM of PM/AM protocol, respectively, Fig. 6).

$A C T H$ response in relation to basal plasma cortisol. When the cumulative ACTH response for each individual on the two morning trials were compared with the baseline levels of cortisol in plasma, there was a significant and positive correlation

Table II. Levels of Cortisol in Plasma during Each of Four Tests Described in Text

\begin{tabular}{|c|c|c|c|c|}
\hline & \multicolumn{2}{|c|}{ AM/PM protocol } & \multicolumn{2}{|c|}{ PM/AM protocol } \\
\hline & AM response & PM response & AM response & PM response \\
\hline & \multicolumn{4}{|c|}{$m g / d l$} \\
\hline Pretest cortisol & $16.36 \pm 2.98$ & $3.25 \pm 0.78$ & $12.2 \pm 0.88$ & $2.73 \pm 0.64$ \\
\hline Basal cortisol & $14.02 \pm 6.69$ & $2.6 \pm 1.29$ & $11.78 \pm 1.7$ & $2.94 \pm 1.69$ \\
\hline Maximum increment in cortisol & $16.64 \pm 7.21$ & $13.42 \pm 5.54$ & $9.54 \pm 5.80$ & $11.24 \pm 3.37$ \\
\hline Cumulative cortisol & $175.24 \pm 112.76$ & $87.98 \pm 34.50$ & $78.70 \pm 45.23$ & $69.98 \pm 30.83$ \\
\hline \multicolumn{5}{|l|}{ Dose at which significant cortisol } \\
\hline increase occurred & $0.1 \mathrm{IU}$ & $1 \mathrm{IU}$ & $1 \mathrm{IU}$ & $1 \mathrm{IU}$ \\
\hline
\end{tabular}




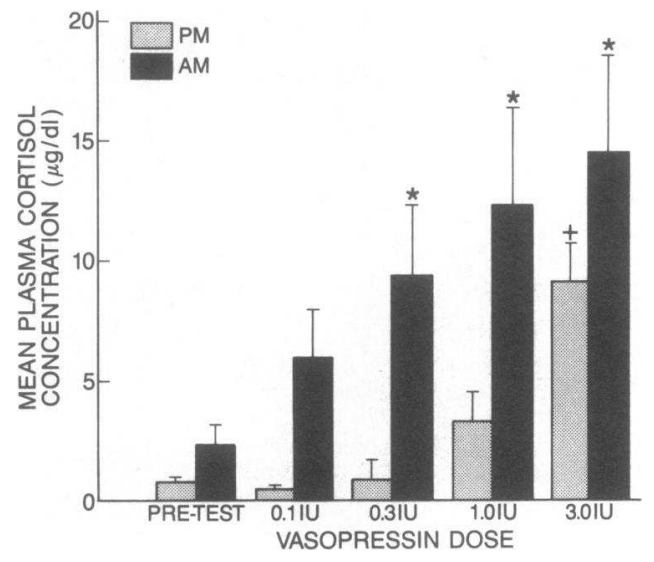

Figure 4. Dose-response increase of cortisol in the morning of the AM/PM protocol versus the evening of the PM/AM protocol. Each bar is the mean of the three cortisol samples for each subject after each dose of AVP. Baseline subtracted as in Fig. 3. The dose-response curve for cortisol is significantly shifted to the left in the morning of the AM/PM protocol when compared with the evening of the PM/AM protocol. Cortisol was significantly increased in the AM of the AM/PM protocol after $0.3 \mathrm{U}$ of AVP $(* P<0.05$, when compared with baseline value). The increase was not significant until $3 \mathrm{U}$ of AVP in the evening of the PM/AM protocol $(+P<0.05$, when compared with baseline value).

$(P<0.05)$. However, there was no significant correlation between the ACTH response and the baseline cortisol in the evening trials when the baseline cortisols were all low.

AVP results. When plasma AVP levels after each graded bolus of vasopressin were compared for each of the protocols, the mean values were not significantly different at any time points except in two isolated samples, the 55-min sample for the AM of the AM/PM protocol and the 60-min sample for the PM of the AM/PM protocol. These small differences were not felt to be meaningful because the samples immediately before

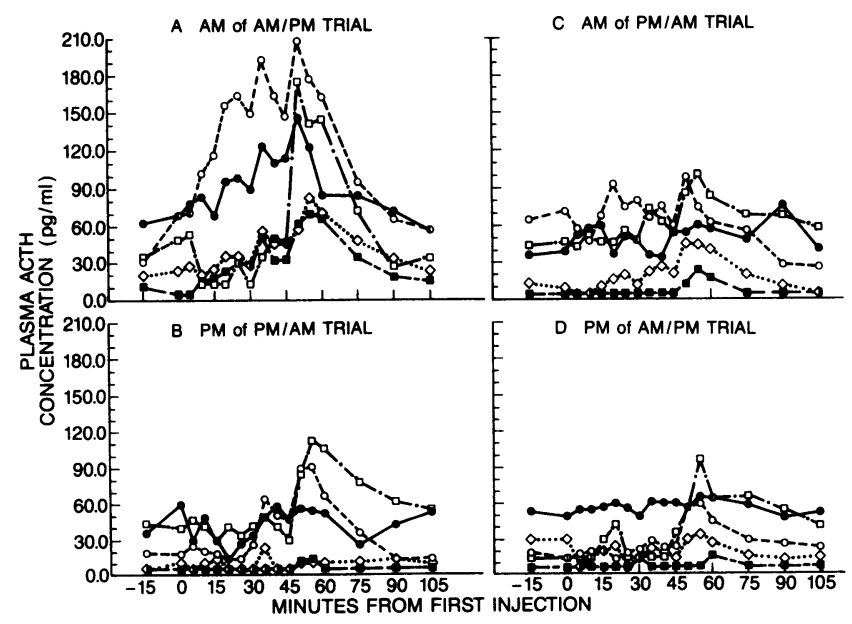

Figure 5. Effect of prior administration of AVP on subsequent ACTH response to AVP for individual subjects. The ACTH response to vasopressin administered in the morning was significantly blunted if vasopressin had been administered the prior evening, AM of the PM/AM protocol $(C)$ versus AM of the AM/PM protocol $(A)$. There was no difference in the response in the evening regardless of the prior administration of AVP, PM of the PM/AM protocol $(B)$ versus PM of the AM/PM protocol $(D)$.

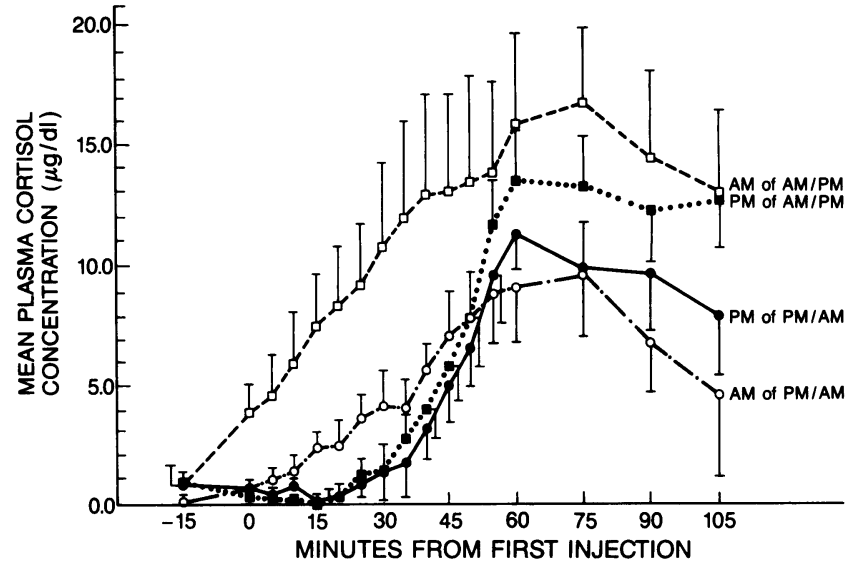

Figure 6. Effect of prior administration of AVP on subsequent cortisol response. Mean levels of cortisol $( \pm$ SEM) for each of the four trials are shown. The cortisol response in the morning of the PM/AM protocol (O) was significantly blunted and the dose-response curve is shifted to the right when compared with the morning response of the AM/PM protocol ( $\square$ ) when no vasopressin was administered previously. There was no significant difference in the cortisol response in the evening of the AM/PM protocol ( $($ ) with prior exposure to vasopressin when compared with the evening of the PM/AM protocol (๑) without prior vasopressin exposure.

and after these points, 50 and $75 \mathrm{~min}$, showed no differences, i.e., there was no trend. More importantly, significant changes in ACTH and cortisol measurements preceded rather than followed the only differences in plasma vasopressin described above.

Mean plasma vasopressin after a 1-U bolus was $146.9 \pm 13.7 \mathrm{pg} / \mathrm{ml}$ while after a 3-U bolus the mean plasma vasopressin was $372.7 \pm 31.8 \mathrm{pg} / \mathrm{ml}$. These levels of vasopressin, although much higher than physiological levels of peripherally measured vasopressin, are within the range of what has been measured in monkey portal blood (26).

\section{Discussion}

The 41-amino acid peptide, CRF, is probably the most important physiologic mediator of ACTH secretion in man. However, even before the isolation of CRF it was recognized that more than one physiologically active principle was present in hypothalamic extracts that possessed ACTH releasing activity $(3,4)$. Recently the hypothalamic peptide that has received the most attention as another potential physiological ACTH secretagogue is vasopressin. Vasopressin is localized anatomically in the external zone of the median eminence in the area of hormone secretion into long portal vessels that feed the anterior pituitary $(27,28)$. High levels of vasopressin have been measured in pituitary portal blood (27), and the content of vasopressin in the external zone is increased during some states of ACTH hypersecretion, i.e., after adrenalectomy in experimental animals (28-32). In direct studies it has also been demonstrated that vasopressin causes release of ACTH $(12-16)$. When used alone, vasopressin is inferior as a secretagogue of ACTH in comparison with $\operatorname{CRF}(9,12,13)$. However, both in the rat (13) and in man (14-16) there is clear synergism between the ACTH releasing activity of CRF and vasopressin, with a greater than additive effect on ACTH release when the 
two are co-administered. While most of the studies that demonstrated synergism between these two secretagogues used experimental protocols in which both secretagogues were administered exogenously, it is reasonable to hypothesize that the administration of one secretagogue would also act synergistically with ambient concentrations of endogenous secretagogues. Evidence in support of this has been reported. ACTH secretion in response to administered CRF was reported as threefold greater during concurrent administration of hypertonic saline, which caused elevated levels of vasopressin (33, 34). We hypothesized that the converse might also be true; that is, exogenously administered vasopressin would act synergistically with endogenous levels of CRF. Indeed, because vasopressin is such a weak secretagogue by itself, the magnitude of the ACTH response to administered vasopressin might depend to a great extent upon the ambient level of endogenous CRF in hypophyseal portal blood. This was given as a possible reason for the greater release of ACTH observed when vasopressin was administered to freely moving rats as compared with rats in which endogenous CRF was blocked by chlorpromazinemorphine-nembutal pretreatment or by anti-CRF antiserum (13).

To test this hypothesis in humans we used a protocol that was designed to produce a dose-response relationship between administered vasopressin and secretion of ACTH. We began with a dose of vasopressin that was estimated to be too low to produce any measurable increase in ACTH $(0.1 \mathrm{U})$ and increased to a maximum of $3 \mathrm{U}$, which was still considerably less than the 5-10 $U$ that have been used in other published studies of synergism in man (14-16). Because the half-life of vasopressin in man is $2-7 \mathrm{~min}(35,36)$ and of ACTH $15 \mathrm{~min}(37)$, we increased the administered dose of vasopressin every 15 min. While administration of vasopressin every $15 \mathrm{~min}$ did result in some cumulative effect on the level of ACTH, with the response to one dose of vasopressin adding to the residual response produced by the previous dose, nonetheless by starting with a low dose it was possible to develop a dose-response curve and to demonstrate shifts in the curve. There was a lower threshold of ACTH response, shift to the left, when the sensitivity of the axis was increased (morning vs. evening), and a shift to the right with a greater threshold response when the axis was dampened (morning response after exposure to vasopressin the previous evening). However, because the effect of the vasopressin doses on ACTH secretion was cumulative, it should not be anticipated that a single isolated bolus of vasopressin would give results similar to those obtained here at any point in the dose response.

To investigate whether endogenous hypophyseal portal levels of CRF could be estimated by synergism with exogenously administered vasopressin, we made use of the wellknown diurnal rhythm of cortisol and ACTH. It is assumed, but not proven, that the diurnal rhythm of ACTH and cortisol is initiated by a diurnal rhythm of CRF, with higher endogenous levels of CRF in the morning and lower levels in the evening (17). This assumption is supported by the results of our studies, and of other recently published reports. In a report in humans with CRF deficiency, pulsatile administration of CRF with more frequent pulses in the morning produced a diurnal pattern of ACTH and cortisol secretion similar to that observed in normal subjects (38), and in another recent report, higher levels of CRF were measured in peripheral plasma in the morning (39). In our study administration of synthetic vasopressin produced a markedly enhanced release of ACTH in the morning as compared with the evening, consistent with synergism of vasopressin with high endogenous CRF in the morning. Note that this result is opposite of that for administration of graded boluses of exogenous CRF, where the greater release of ACTH and cortisol was found in the evening (17-20). In those studies there was a negative correlation between basal cortisol levels and both ACTH and cortisol response to CRF stimulation (17-20, 40). In these previous studies the lesser response of ACTH to CRF in the morning was thought possibly to be due to feedback inhibition at the pituitary by the higher level of ambient cortisol levels in the morning. However, in our studies it was apparent that the pituitary was not markedly inhibited in its ability to release ACTH in the morning, because the release of $\mathrm{ACTH}$ in response to administered vasopressin was greater in the morning. Thus, one alternate explanation for the results obtained with CRF is that endogenous hypophyseal portal levels of CRF are high in the morning, possibly approaching maximal response, and additional exogenously administered CRF caused little further release of $\mathrm{ACTH}$. With this interpretation, the negative correlation between the ACTH response to CRF and the ambient level of cortisol would be explained, because the high level of cortisol reflected a high level of endogenous CRF (40). In contrast, when vasopressin was administered we found the ACTH release was positively correlated with the ambient level of plasma cortisol. We interpret this to support the concept that high levels of CRF are responsible for the high levels of cortisol and that vasopressin acted synergistically with the endogenous CRF in hypophyseal portal blood. Therefore, based on the data above it would be reasonable to conclude that CRF is the major hypothalamic regulator of the ACTH and cortisol diurnal rhythm. However, this leaves unexplained the observation (41) that a diurnal rhythm of ACTH release persists even during continuous administration of CRF. From that study (41) it was suggested that other factors with corticotropin releasing activity (i.e., vasopressin) also participated in the diurnal rhythm of ACTH release. Neither our results nor other published reports would necessarily negate any role of vasopressin in the diurnal rhythm of ACTH, but only suggest that the major secretagogue mediating the diurnal rhythm is CRF.

When the AM trial was preceded by a graded vasopressin infusion on the previous evening (PM/AM protocol), a blunted response of both ACTH and cortisol were observed. There are three possible mechanisms for this observation. First, glucocorticoids are known modulators of CRF-mediated ACTH release (40). They suppress pituitary responsiveness to CRF and possibly also inhibit secretion of CRF through an effect in the hypothalamus $(42,43)$. Second, it has been shown in vitro that exposure of corticotroph cells to various concentrations of dexamethasone down-regulates the CRF specific receptor on the cells in a dose-dependent fashion (44). Finally, pituitary desensitization to AVP may occur (similar to what has been shown for CRF in in vivo animal studies) independently of any steroid feedback (45). The anterior pituitary contains specific receptors for AVP which are distinct from those for hypothalamic CRF $(46,47)$, and prior injections of AVP might cause down-regulation of the AVP specific receptor on pituitary cells (47). To determine which, if any, of the explanations is correct will require further study.

The site of action of vasopressin to enhance the effect of CRF is presumed to be at the level of the pituitary cortico- 
troph. This assumption is based upon several observations. As described above, vasopressin is localized anatomically within the hypothalamic pituitary portal system in a manner that would allow vasopressin to directly stimulate pituitary corticotrophs $(27,28)$. Enhancement by AVP of the effect of CRF to release ACTH has been demonstrated in anterior pituitary cell cultures (48) and in isolated pituitary cell lines (44). With isolated cell lines, vasopressin increases the amount of cyclic AMP generated by administered CRF (49). In addition, both CRF and vasopressin receptors have been identified on rat anterior pituitary cells, and these appear to be independent receptors for which the alternate secretagogue is not competitive (44). Initial studies characterizing the vasopressin receptor on the anterior pituitary indicated that the corticotroph secreting activity was via a $V_{1}$ or pressor receptor (50). However, subsequent studies have produced disparate results on this point. In intact animals (e.g., dogs [51] and rats [unpublished results from our laboratory]), the ACTH secreting activity of intravenously administered vasopressin was completely blocked by a specific antagonist to the $\mathrm{V}_{1}$ receptor, $\mathrm{d}\left(\mathrm{CH}_{2}\right)_{5}$ MeTyrAVP, and the effect of vasopressin was mimicked by $V_{1}$ agonists but not by $V_{2}$ (antidiuretic) agonists (50). But, in studies of rat pituitary in vitro there was a poor correlation between the corticotropin releasing activity of vasopressin analogues and the $V_{1}$ receptor or pressor activity $(52,53)$. Likewise, the binding of vasopressin to rat anterior pituitary cell membrane preparations was not displaced by a $\mathrm{V}_{1}$ antagonist (54). Baertschi and Friedli reported that the activity of vasopressin to act synergistically with CRF to release ACTH from suspensions of rat anterior pituitary cells was not blocked by two antipressor antagonists (55). Thus, there is a discrepency between studies done in vivo and studies in vitro. Studies in vivo have uniformly demonstrated that the ACTH secretagogue activity of vasopressin was related to the pressor action of vasopressin and was inhibited by antipressor antagonists. In vitro, while the enhancement of CRF action could be obtained with vasopressin, that action of vasopressin was not uniformly related to the pressor effect and was not inhibited by antipressor antagonists. It has been suggested that the vasopressin receptor on the anterior pituitary is distinct from both the $V_{1}$ and the $V_{2}$ receptors, and is a new class $\left(V_{3}\right)$ of receptor $(54$, 55). Until these issues are resolved, studies such as ours that use the natural hormone, AVP, may provide the most physiologically relevant information.

We should emphasize that we used vasopressin as a test substance which gave data to support a diurnal variation of CRF secretion. These observations provide no further insight into the role of vasopressin (or CRF) as a physiologic regulator of ACTH release in adrenal insufficiency or in the variety of stresses that stimulate ACTH release. This subject has recently been reviewed in detail (56). However, one can use the knowledge of the diurnal variation in the ACTH responses to vasopressin and to CRF to interpret other studies in which stimulation of the hypothalamic-pituitary-adrenal axis was produced by more physiologic stimuli. Both administration of a pyrogen (57) and of insulin (hypoglycemia) $(58,59)$ have been shown to produce a greater release of cortisol in the evening than in the morning. Because this pattern of response is similar to that obtained with administered CRF and opposite to that obtained with administered vasopressin, we would suggest that CRF is the more likely mediator of these stress responses in humans.
In our study each test was done once in each subject and there was a considerable range in the response from subject to subject. This variability in response is probably intrinsic to the subject because (as can be seen from Figs. 1 and 2) the rank order of the subject's response was rather constant among the four times of testing. Because of the variability from person to person, more useful data might be obtained by comparison of the response to administered vasopressin with the response to administered CRF in the same subject. A heightened response to vasopressin coupled with a lower response to CRF would indicate that CRF was the important modulator of the increased ACTH in that particular setting. Such studies might be useful, for example, in defining subsets of Cushing's disease in which CRF hypersecretion was important, or in defining abnormalities of CRF secretion as might occur in certain patients with depression.

In summary, this study confirmed that vasopressin stimulates secretion of ACTH, and demonstrated that exogenously administered vasopressin acts synergistically with endogenous CRF in the release of ACTH. The morning and evening responses of ACTH to administered vasopressin are the opposite of those to administered CRF (17-20). The greatest ACTH response was not in the morning after vasopressin infusion, but in the evening after CRF infusion. These data provide indirect evidence that the diurnal rhythm of ACTH and cortisol is secondary to a diurnal rhythm of CRF secretion. The protocol demonstrates that a vasopressin stimulation test may be useful in determining the relative level of CRF secretion, and may be applicable to future research on the pathophysiology of disorders of ACTH secretion.

\section{Acknowledgments}

We acknowledge the support of Jan McWilliams and the nursing staff of The Clinical Research Center, Presbyterian University Hospital, Pittsburgh, PA, Jean Miewald for statistical assistance, and Yvonne Jones and Jane Pennebaker for secretarial assistance.

The studies were supported by The General Clinical Research Center NIH grant M01-RR-00056, NIH grants AM-16166 (A. G. Robinson) and MH-34390 (D. B. Jarrett), and by the Veterans Administration (J. G. Verbalis).

\section{References}

1. Saffran, M., A. V. Schally, and B. G. Bentey. 1955. Stimulation of the release of corticotropin from the adenohypophysis by a neurohypophyseal factor. Endocrinology. 57:439-444.

2. Guillemin, R., and B. Rosenberg. 1955. Humoral hypothalamic control of anterior pituitary: a study with combined tissue cultures. Endocrinology. 57:599-607.

3. Krieger, D. T., and E. A. Zimmerman. 1977. The nature of CRF and its relationship to vasopressin. In Clinical Neuroendocrinology. L. Martini and G. M. Besser, editors. Academic Press, Inc., New York. 364-392.

4. Yates, F. E., and J. W. Maran. 1974. Stimulation and inhibition of adrenocorticotropin release. In Handbook of Physiology, Section 7: Endocrinology, Vol. 4. E. Knobil and W. H. Sawyer, editors. American Physiological Society, Washington, D.C. 367-404.

5. Brostoff, J., V. H. T. James, and J. Landon. 1968. Plasma corticosteroid and growth hormone response to lysine-vasopressin in man. J. Clin. Endocrinol. Metab. 28:511-518.

6. McCann, S. M. 1953. Effect of hypothalamic lesions on the adrenal cortical response to stress in the rat. Am. J. Physiol. 175:13-20. 
7. Sirett, N. E., and H. G. Purves. 1973. The assay of corticotrophin-releasing factor in ACTH "primed" rats. In Brain-Pituitary-Adrenal Interrelationships. A. Brodish and E. S. Redgate, editors. S. Karger, Basel. pp 79-98.

8. Fleischer, N., and W. Vale. 1968. Inhibition of vasopressin-induced ACTH release from the pituitary by glucocorticoids in vitro. Endocrinology. 83:1232-1236.

9. Portanova, R., and G. Sawyers. 1973. Isolated pituitary cells: CRF-like activity of neurohypophyseal and related polypeptides. Proc. Soc. Exp. Biol. Med. 143:661-666.

10. Pearlmutter, A. F., L. Dokar, A. Kong, R. Miller, and M. S. Saffron. 1980. Is corticotropin-releasing factor modulated vasopressin? Nature (Lond). 283:697-698.

11. Gillies, G., and P. J. Lowry. 1982. Corticotropin-releasing hormone and its vasopressin component. Front Neuroendocrinol. 7:45-75.

12. Vale, W., and C. Rivier. 1977. Substances modulating the secretion of ACTH by cultured anterior pituitary cells. Fed. Proc. 36:2094-2099.

13. Rivier, C., and W. Vale. 1983. Interaction of corticotropin-releasing factor and arginine vasopressin on adenocorticotropin secretion in vivo. Endocrinology. 113:939-942.

14. DeBold, C. R., W. R. Sheldon, G. S. DeCherney, R. V. Jackson, A. N. Alexander, W. Vale, J. Rivier, and D. N. Orth. 1984. Arginine vasopressin potentiates adrenocorticotropin release induced by ovine corticotropin-releasing factor. J. Clin. Invest. 73:533-538.

15. Lamberts, S. W. J., T. Verleun, R. Oosteron, F. DeJong, and W. H. L. Hackeng. 1984. Corticotropin-releasing factor (ovine) and vasopressin exert a synergistic effect on adrenocorticotropin release in man. J. Clin. Endocrinol. Metab. 58:298-303.

16. Liu, J. H., K. Muse, P. Contreras, D. Gibbs, W. Vale, J. Rivier and S. C. C. Yen. 1983. Augmentation of ACTH-releasing activity of synthetic corticotropin releasing factor (CRF) by vasopressin in women. J. Clin. Endocrinol. Metab. 57:1087-1089.

17. Chrousos, G. P., T. H. Schuermeyer, J. Doppman, E. H. Oldfield, H. M. Schulte, P. W. Gold, and D. L. Loriaux. 1985. Clinical applications of corticotropin-releasing factor. Ann. Intern. Med. 102:344-358.

18. DeCherney, G. S., C. R. DeBold, R. V. Jackson, W. R. Sheldon, D. P. Island, and D. N. Orth. 1985. Diurnal variation in the response of plasma adrenocorticotropin and cortisol to intravenous ovine corticotropin-releasing hormone. J. Clin. Endocrinol. Metab. 61:273-279.

19. Schulte, H. M., G. P. Chrousos, E. H. Oldfield, P. W. Gold, G. B. Cutler, Jr., and D. L. Loriaux. 1985. Ovine corticotropin-releasing factor administration in normal men. Horm. Res. (Basel). 21:6974.

20. Tsukada, T., Y. Nakai, T. Koh, S. Tsujii, and H. Imura. 1983. Plasma adrenocorticotropin and cortisol responses to intravenous injection of corticotropin-releasing factor in the morning and evening. $J$. Clin. Endocrinol. Metab. 57:869-871.

21. Rivier, C., M. Brownstein, J. Spiess, J. Rivier, and W. Vale. 1982. In vivo corticotropin-releasing factor-induced secretion of adrenocorticotropin B-endorphin and corticosterone. Endocrinology. 110:272-278.

22. Copinschi, G., M. Beyloos, D. Bosson, D. Desir, J. Golstein, C. Robyn, P. Linkowski, J. Mendlewicz, and J. R. M. Franckson. 1983. Immediate and delayed alterations of adrenocorticotropin and cortisol nyctohemeral profiles after corticotropin-releasing factor in normal man. J. Clin. Endocrinol. Metab. 57:1287-1291.

23. Schurmeyer, T. H., P. C. Avgerinos, P. W. Gold, W. T. Gallucci, T. P. Tomai, G. B. Cutler, Jr., D. L. Loriaux, and G. P. Chrousos. 1984. Human corticotropin-releasing factor in man: pharmacokinetic properties and dose-response of plasma adrenocorticotropin and cortisol secretion. J. Clin. Endocrinol. Metab. 59:11031108.

24. Salacinksi, P. R. P., C. McLean, J. E. C. Sykes, V. V. ClementJones, and P. J. Lowry. 1981. Iodination of proteins, glycoproteins and peptides using a solid-phase oxidizing agent, 1,3,4,6-Tetrachlor-3,6 diphenyl glycoluril (IODO-GEN). Anal. Biochem. 117:136-146.

25. Rodbard, D. W., W. Bridson, and P. L. Rayford. 1969. Rapid calculation of radioimmunoassay results. J. Lab. Clin. Med. 74:770781.

26. Uretsky, B. F., J. G. Verbalis, T. Generalovich, A. Valdes, and P. S. Reddy. 1985. Plasma vasopressin response to osmotic and hemodynamic stimuli in heart failure. Am. J. Physiol. 248(Heart Circ. Physiol. 17):H396-H402.

27. Zimmerman, E. A., P. W. Carmel, M. K. Husain, M. Ferin, M. Tannenbaum, A. G. Frantz, and A. G. Robinson. 1973. Vasopressin and neurophysin: high concentrations in monkey hypophyseal portal blood. Science (Wash. DC). 182:925-927.

28. Stillman, M., S. Recht, S. Rosario, S. Seif, A. G. Robinson, and E. A. Zimmerman. 1977. The effects of adrenalectomy and glucocorticoid replacement on vasopressin and vasopressin-neurophysin in the zona externa of the median eminence of the rat. Endocrinology. 101:42-49.

29. Sawchenko, P. E., L. W. Swanson, and W. W. Vale. 1984. Co-expression of corticotropin-releasing factor and vasopressin immunoreactivity in paraventricular neurosecretory neurons of the adrenalectomized rat. Proc. Nat. Acad. Sci. USA. 81:1883-1887.

30. Tramu, G., C. Croix, and A. Pillez. 1983. Ability of the CRF immunoreactive neurons of the paraventricular nucleus to produce a vasopressin-like material. Neuroendocrinology. 37:467-469.

31. Wolfson, B., R. W. Manning, L. G. Davis, R. Arentzen, and F. Baldino, Jr. 1985. Co-localization of corticotropin releasing factor and vasopressin mRNA in neurons after adrenalectomy. Nature (Lond.). 315:59-61.

32. Roth, K. A., E. Weber, and J. D. Berckas. 1982. Immunoreactive corticotropin releasing factor (CRF) and vasopressin are colocalized in an subpopulation of the immunoreactive cells in the paraventricular nucleus of the hypothalamus. Life Sci. 31:1857-1860.

33. Milsom, S. R., J. V. Conaglen, R. A. Donald, E. A. Espiner, M. G. Nicholls, and J. H. Livesey. 1985. Augmentation of the response to $\mathrm{CRF}$ in man: relative contributions of endogenous angiotensin and vasopressin. Clin. Endocrinol. 22:623-628.

34. Rittmaster, R. S., G. B. Cutler, Jr., P. W. Gold, D. D. Brandon, T. Tomai, D. L. Loriaux, and G. P. Chrousos. 1987. The relationship of saline-induced changes in vasopressin secretion to basal and corticotropin-releasing hormone-stimulated adrenocorticotropin and cortisol secretion in man. J. Clin. Endocrinol. Metab. 64(2):371-376.

35. Gazis, D., and W. H. Sawyer. 1978. Estimation of plasma half-lives of vasopressin analogs from vasopressin responses by curvefitting. Proc. Soc. Exp. Biol. Med. 157:584-589.

36. Beardwell, C. G. 1971. Radioimmunoassay of arginine vasopressin in human plasma. J. Clin. Endocrinol. Metab. 33:254-260.

37. Sayers, G., and R. H. Travis. 1970. Adrenocorticotrophic hormone; adrenocortical steroids and their synthetic analogs. In The Pharmacological Basis of Therapeutics. L. S. Goodman and A. Gilman, editors. Macmillan Press, New York. 1604-1642.

38. Avgerinos, P. C., T. H. Schurmeyer, P. W. Gold, T. P. Tomai, D. L. Loriaux, R. J. Sherins, G. B. Cutler, Jr., and G. P. Chrousos. 1986. Administration of human corticotropin-releasing hormone in patients with secondary adrenal insufficiency: restoration of the normal cortisol secretory pattern. J. Clin. Endocrinol. Metab. 62:816-821.

39. Watabe, T., KK. Tanaka, M. Kumagae, S. Itoh, M. Hasegawa, T. Horiuchi, S. Miyabe, H. Ohno, and N. Shimizu. 1987. Diurnal rhythm of plasma immunoreactive corticotropin-releasing factor in normal subjects. Life Sci. 40:1651-1655.

40. Hermus, A. R. M. M., G. F. F. M. Pieters, A. G. H. Smals, T. H. J. Benraad, and P. W. C. Kloppenborg. 1984. Plasma adrenocorticotropin, cortisol and aldosterone responses to corticotropin-releasing factor: modulatory effect of basal cortisol levels. J. Clin. Endocrinol. Metab. 58:187-191.

41. Schulte, H. M., G. P. Chrousos, P. W. Gold, J. D. Booth, E. H. Oldfield, G. B. Cutler, Jr., and D. L. Loriaux. 1985. Continuous ad- 
ministration of synthetic ovine corticotropin-releasing factor in man. J. Clin. Invest. 75:1781-1785.

42. Yasuda, N., M. A. Greer, and T. Aizawa. 1982. Corticotropinreleasing factor. Endocr. Rev. 3:123-140.

43. Chrousos, G. P., H. M. Schulte, E. H. Oldfield, P. W. Gold, G. B. Cutler, Jr., and D. L. Loriaux. 1984. The corticotropin-releasing factor stimulation test: an aid in the differential diagnosis of Cushing's syndrome. N. Engl. J. Med. 310:622-627.

44. Rosendale, B. E., D. B. Jarrett, and A. G. Robinson. 1987. Identification of a corticotropin-releasing factor-binding protein in the plasma membrane of AtT-20 mouse pituitary tumor cells and its regulation by dexamethasone. Endocrinology. 120:2357-2366.

45. Rivier, C., and W. Vale. 1983. Influence of the frequency of ovine corticotropin-releasing factor administration on adrenocorticotropin and corticosterone secretion in the rat. Endocrinology. 113:1422-1426.

46. Lutz-Bucher, B., B. Koch, and C. Mialhe. 1977. Comparative in vitro studies on $\mathrm{CRF}$ activity of vasopressin and hypothalamic median eminence extract. Neuroendocrinology. 23:181-192.

47. Koch, B., and B. Lutz-Bucher. 1985. Specific receptors for vasopressin in the pituitary gland: evidence for down-regulation and desensitization to adrenocorticotropin-releasing factors. Endocrinology. 116:671-676.

48. Vale, W., J. Vaughan, M. Smith, G. Yamamoto, J. Rivier, and C. Rivier. 1983. Effects of synthetic ovine corticotropin-releasing factor, glucocorticosteroids, catecholamines, neurohypophyseal peptides and other substances on cultured corticotrophic cells. Endocrinology. 113:1121-1131

49. Giguere, V., and F. Labrie. 1982. Vasopressin potentiates cyclic AMP accumulation and ACTH release induced by corticotropin-releasing factor (CRF) in rat anterior pituitary cells in culture. Endocrinology. 111:1752-1754.

50. Aizawa, T., N. Yasuda, M. A. Greer, and H. W. Sawyer. 1982.
In vivo adrenocorticotropin-releasing activity of neurohypophyseal hormones and their analogs. Endocrinology. 110:98-104.

51. Schwartz, J., and I. A. Reid. 1986. Characteristics of the receptors which mediate the stimulation of ACTH secretion by vasopressin in conscious dogs. Neuroendocrinology. 42:93-96.

52. Knepel, W., L. Homolka, M. Vlaskovska, and D. Nutto. 1984. In vitro adrenocorticotropin/B-endorphin-releasing activity of vasopressin analogs is related neither to pressor nor to antidiuretic activity. Endocrinology. 114:1797-1804.

53. Knepel, W., L. Homolka, and M. Vlaskovska. 1983. In vitro CRF activity of vasopressin analogs is not related to pressor activity. Eur. J. Pharmacol. 91:115-118.

54. Antoni, F. A. 1984. Novel ligand specificity of pituitary vasopressin receptors in the rat. Neuroendocrinology. 39:186-188.

55. Baertschi, A. J., and M. Friedli. 1985. A novel type of vasopressin receptor on anterior pituitary corticotrophs? Endocrinology. 116:499-502.

56. Antoni, F. 1986. Hypothalamic control of adrenocorticotropin secretion: advances since the discovery of 41-residue corticotropin-releasing factor. Endocr. Rev. 7:351-378.

57. Takebe, K., C. Setaishi, M. Hirama, M. Yamamoto, and Y. Horiuchi. 1966. Effect of bacterial pyrogen on the pituitary-adrenal axis at various times in 24 hours. J. Clin. Endocrinol. Metab. 26:437442.

58. Ichikawa, Y., M. Nishikai, M. Kawagoe, K. Yoshida, and M. Homma. 1972. Plasma corticotropin, cortisol and growth hormone responses to hypoglycemia in the morning and evening. J. Clin. Endocrinol. Metab. 34:895-898.

59. Nathan, R. S., E. J. Sachar, G. Langer, M. A. Tabrizi, and F. S. Halpern. 1979. Diurnal variation in the response of plasma prolactin, cortisol and growth hormone to insulin-induced hypoglycemia in normal men. J. Clin. Endocrinol. Metab. 49:231-235. 